\title{
MODEL PREDICTING COST BENEFIT ANALYSIS (CBA) OF ACCIDENT PREVENTION ON CONSTRUCTION PROJECTS
}

\author{
E. IKPE, F. HAMMOND, D. PROVERBS \& D. OLOKE \\ School of Engineering and Built Environment, University of Wolverhampton, UK.
}

\begin{abstract}
Health and safety issues are major concerns in the United Kingdom (UK) construction industry. Evidence suggests that research studies on construction health and safety management issues have yet to lead to a significant reduction in the number of accidents. To tackle the causes of days lost through accidents and to improve health and safety performance in the construction industry, the industry needs to understand the cost benefit analysis (CBA) of accident prevention. The paper reviewed the rate of accidents in the UK construction industry and presents a model predicting CBA of accident prevention on construction projects. A quantitative method approach was used to collect data from health and safety managers in the UK construction industry for the survey. A total of 79 contractors (small, medium and large) participated in the questionnaire survey. A simple linear regression model was adopted to identify the effect of total costs of accident prevention on benefits of accident prevention. The result revealed that costs of accident prevention are significantly associated with benefits of accident prevention. The model predicted that the more the contractors spend on accident prevention the more the benefit of accident prevention they derived. This is part of a wider study to improve the management of health and safety and to propose a way forward for safer and healthier construction sites.

Keywords: accident prevention, construction projects, cost benefit analysis, health and safety.
\end{abstract}

\section{INTRODUCTION}

The construction industry is regarded as a hazardous and high-risk environment where workers face a greater risk of work-related fatality or injury than workers in other industries. Although the industry has been paying significantly greater attention to health and safety in recent years with the aim of reducing accidents and injuries, it is consistently responsible for the largest number of fatal work injuries than any industry in the UK [1]. Based on an average, in the past 5 years, construction fatalities accounted for around $30 \%$ of all worker deaths [1]. In the last 25 years, over 2800 people died from injuries from construction work and many more were injured or made ill [1]. On the basis of these statistics, it has been established that construction has the second worst industry record for health and safety next to agriculture [2].

Table 1 shows the accident occurrence in the UK construction industry from 2000/01 to 2008/09. These figures confirm the need for significant improvement in health and safety performance in the construction industry. According to Edwards and Nicholas [3], accident figures in the construction industry have remained consistently high, whereas the accident figures for other industry sections have steadily declined. This trend indicates that additional measures must be introduced to reduce the rate of accidents and subsequently help to improve health and safety performance.

As can be seen from Table 1, the number of fatal injuries fell from 105 in 2000/01 to 59 in $2005 / 06$ but rose by $23.4 \%$ to 77 in 2006/07, declined in 2007/08 and 2008/09, evidence that whilst significant improvement has been made through the various initiatives implemented over the years, these initiatives may still not be adequate in the effort to secure accident free working environments. The $23.4 \%$ increase in $2006 / 07$ is particularly worrying. Indeed, it 
Table 1: HSE [10] statistics of fatal, major and over-3-day injuries in the UK construction industry.

\begin{tabular}{|c|c|c|c|c|c|c|c|c|c|}
\hline & \multicolumn{9}{|c|}{ Year } \\
\hline & $2000 / 01$ & $01 / 02$ & $02 / 03$ & 03/04 & $04 / 05$ & $05 / 06$ & $06 / 07$ & $07 / 08$ & 08/09 \\
\hline Fatal injuries & 105 & 80 & 70 & 71 & 72 & 59 & 77 & 72 & 52 \\
\hline Annual $\Delta \%$ & - & $-24 \%$ & $-12.5 \%$ & $1.4 \%$ & $1.4 \%$ & $-22 \%$ & $23.4 \%$ & $-6.5 \%$ & $-27.8 \%$ \\
\hline Major injuries & 4708 & 4595 & 4720 & 4728 & 4486 & 4472 & 4430 & 4415 & 3937 \\
\hline Annual $\Delta \%$ & - & $-2.4 \%$ & $2.7 \%$ & $0.2 \%$ & $-5 \%$ & $-0.3 \%$ & $-1 \%$ & $-0.3 \%$ & $10.8 \%$ \\
\hline $\begin{array}{l}\text { Over-3-day } \\
\text { injuries }\end{array}$ & 9796 & 9695 & 9578 & 8995 & 8250 & 8291 & 8299 & 8188 & 7379 \\
\hline Annual $\Delta \%$ & - & $-1 \%$ & $-1 \%$ & $-6 \%$ & $-8 \%$ & $0.5 \%$ & $0.1 \%$ & $1.3 \%$ & $9.8 \%$ \\
\hline
\end{tabular}

Source: Ref. [36].

can be argued that even the loss of one life is too many and, therefore, current accident levels and the resulting fatalities are still too high. Major injuries fell from 4708 (in 2000/01) to 3937 (in 2008/09) representing an overall decline of about 16\%, and over-3-day injury also fell from 9796 to 7379 (24.7\%), which suggests some improvement on non-fatal injuries. The rate of fatal and non-fatal injuries in construction in recent years has shown a downward trend, however, it can be argued that this improvement is not considerable enough to conclude that safe working environments have been achieved across the industry. Indeed in both major and over-3-day injuries, there appears to be stagnation or even marginal increases in the level of accidents in the last 3 years of the survey shown in Table 1.

Together with the significant upturn in fatalities $(23.4 \%$ in $2006 / 07)$, these statistics are all more surprising when all the stringent health and safety requirements imposed on the industry over recent years by the Health and Safety Executive (HSE) are considered. Clearly, the statistics reinforced the consensus that there is a need to improve health and safety performance in the construction industry. Regardless of the hazardous or high-risk nature of construction, all accidents are not only foreseeable but also preventable [4], and it is unethical and illegal for employers to place their employees and others at unreasonable risk [5].

\section{LITERATURE REVIEW}

The UK Health and Safety Executive (HSE) in 2005 developed on-line interactive tools for contractors to assess the cost of accidents to their organisations. These costs, as identified by HSE, are: lost time; sick pay; damage or loss of product and raw materials; repairs to plant and equipment; extra wages, overtime working and temporary labour; production delays; investigation time; fines; loss of contracts; legal costs; and loss of business reputation; sickness absence; overtime payments; lost production; missed deadlines; cost of recruiting and retraining of staff. Although the developed tool provides useful guidance to contractors on what accidents can cost them, however, it is not sufficiently detailed to specifically assist contractors in developing effective and efficient health and safety management systems. For instance, the tool refers to cost estimates of accidents but does not take into account what are 
the actual costs and the benefits of accident prevention. The on-line developed tool focussed solely on what accidents could cost organisations. It can further be argued that the extent to which the tool has been utilised in the construction industry to realise the intended aims and objectives are still vague. Take for instance the fatal accident occurrence in 2006/07 that rose sharply from 59 in 2005/06 to 77 (23.4\%) (refer to Table 1). Thus, this HSE initiative is not adequate to guide contractor's decision making on costs and benefits of accident prevention. Relying on such a cost calculation without calculating the benefits obviously cannot guide contractors in their decisions making.

When accidents do occur, however, they not only tarnish the image of the industry and make it difficult to attract skilled labour, but also more importantly from a business perspective, they tend to be very expensive. Accidents can give rise to serious costs and have major financial impact particularly on small and medium construction companies [6]. These costs can be classified as either direct costs or indirect costs [7] which together place a large economic burden on contractors, clients and society.

\section{COSTS OF HEALTH AND SAFETY}

The costs incurred by contractors on account of health and safety are divided into two categories both of which contribute to the overall financial losses of contractors [8]. The first is the 'costs of accident prevention (health and safety measures)'. According to HSE [9], Tang et al. [10], Ferret and Hughes [4], they are expenses invested directly by contractors to prevent accidents. The second is costs of accident (direct and indirect) which arise from the occurrence of accidents despite the fact that safety measures were in place.

\subsection{Direct costs of accident}

Direct cost is the actual costs that can be directly attributable to injuries and fatalities $[9,10]$. It refers to expenditure when accidents occur including insurance; damage to buildings and equipments or vehicles; damage to the product; expenditure on medical care; cost of investigation; legal costs; death; permanent disability; worker illness; losses of current production; pains as well as discomfort associated with accidents $[4,7,10,12]$.

An estimate of the direct cost to employers of accidents in construction projects has been provided by Fellows et al. [8] as shown in Table 2 and was calculated as $£ 433.22$ per employee per annum. Although the basis of this calculation and the assumptions on which it is based can be challenged (for instance its assumption of an accident rate of 33 accidents per 1000 workers), this figure is instructive and provides some idea of the scale of the problem. To put this into proper context, and using the same accident rate of 33 accidents per 1000 workers used by Fellows et al. a small contractor employing up to 30 employees is likely to have one accident per annum and will incur a cost of $£ 12,996.60$ per annum $(30 \times £ 433.22)$. It should be noted that this is a conservative figure as observed by Fellows et al. [8] in the original calculations and could be much higher.

\subsection{Indirect costs of accident}

Indirect costs refer to costs that may not be covered by insurance and are the less tangible costs that result from accidents [4]. These indirect costs include: cleaning up; hire costs of temporary equipment; waste disposal; temporary labour; costs of advising and consulting experts; lost time, sick pay, overtime working and temporary labour; and loss of business 
Table 2: Direct costs of accidents to employers.

\begin{tabular}{|c|c|c|c|c|}
\hline $\begin{array}{l}\text { Predicted } \\
\text { accident rates }\end{array}$ & Category & $\begin{array}{l}\text { Actual } \\
\text { number }\end{array}$ & Loss & Value $(£)$ \\
\hline 1 & $\begin{array}{l}\text { Reported } \\
\text { accident. Loss to } \\
\text { Company: } 200 \% \\
\text { of wage rate }\end{array}$ & 33 & $\begin{array}{c}33 \times 20 \text { days }=660 \text { days lost } \\
\text { per } 1000 \text { workers at } 200 \%= \\
1,320 \text { days at } £ 70 \text { per day }\end{array}$ & 92,400 \\
\hline 10 & Minor accidents & 330 & $\begin{array}{l}330 \times 2 \mathrm{~h}=660 \text { hours lost } \\
\text { per } 1,000 \text { workers }=73 \\
\text { days at } 200 \%=146 \text { days } \\
\text { at } £ 70 \text { per day }\end{array}$ & 10,220 \\
\hline \multirow[t]{2}{*}{33} & Property damage & 990 & $990 \times £ 300$ & 297,000 \\
\hline & Insurance costs & & $\begin{array}{c}20 \text { p per } £ 100 \text { wages for } \\
1,000 \text { workers }((0.2 \times \\
16,800) / 100) \times 1000\end{array}$ & 33,600 \\
\hline $\begin{array}{l}\text { Total cost per } 1,000 \\
\text { employees }\end{array}$ & & & & 433.220 \\
\hline $\begin{array}{l}\text { Cost per employee } \\
\text { (per annum) }\end{array}$ & & & & 433.22 \\
\hline
\end{tabular}

Source: Ref. [8].

reputation $[4,7,10,12]$. It has been claimed by several authors that most of the company costs are those stemming from the indirect costs of accidents (production losses) (cf. $[4,8,13]$ ). According to Fellow et al. [8] indirect costs are up to four times higher than direct costs of accidents. Indeed, Ferret and Hughes [4] estimate that indirect costs are up to 36 times higher than direct costs of accidents. Based on the illustrative calculation of $£ 12,996.60$ per annum direct costs in the preceding subsection, indirect costs could potentially range from $£ 51,986.40$ $(4 \times £ 12,996.60)$ to $£ 467,877.60(36 \times £ 12,996.60)$. Clearly, it can be argued that accident costs of this magnitude will have significant impact on the bottom line of construction firms, especially small contractors whose turnover is less than $£ 5 \mathrm{~m} \mathrm{[14].}$

\subsection{Costs of accident prevention}

The cost of accident prevention is the cost of resources spent by contractors in implementing health and safety measures in order to comply with their health and safety obligations. It refers to costs related to the following: first aid; PPE; safety training; safety promotion; safety personnel (see [7, 10, 12]) which contractors must legally comply to put in place. Thus, this category of cost is very often at the fore of considerations of the costs of health and safety. However, when undertaking a CBA of accident prevention, the relevant costs to consider are these costs associated with the preventative measures implemented by contractors to eliminate accidents or minimise their impacts. For the purposes of the research, therefore, the emphasis is placed on accident prevention costs.

As shown in Fig. 1 and argued cogently in Fellows et al. [8], costs expended on accident prevention lead to a reduction in risk and consequently a reduction in accidents. A reduction in accidents can influence construction performance and overall profitability by reducing the 


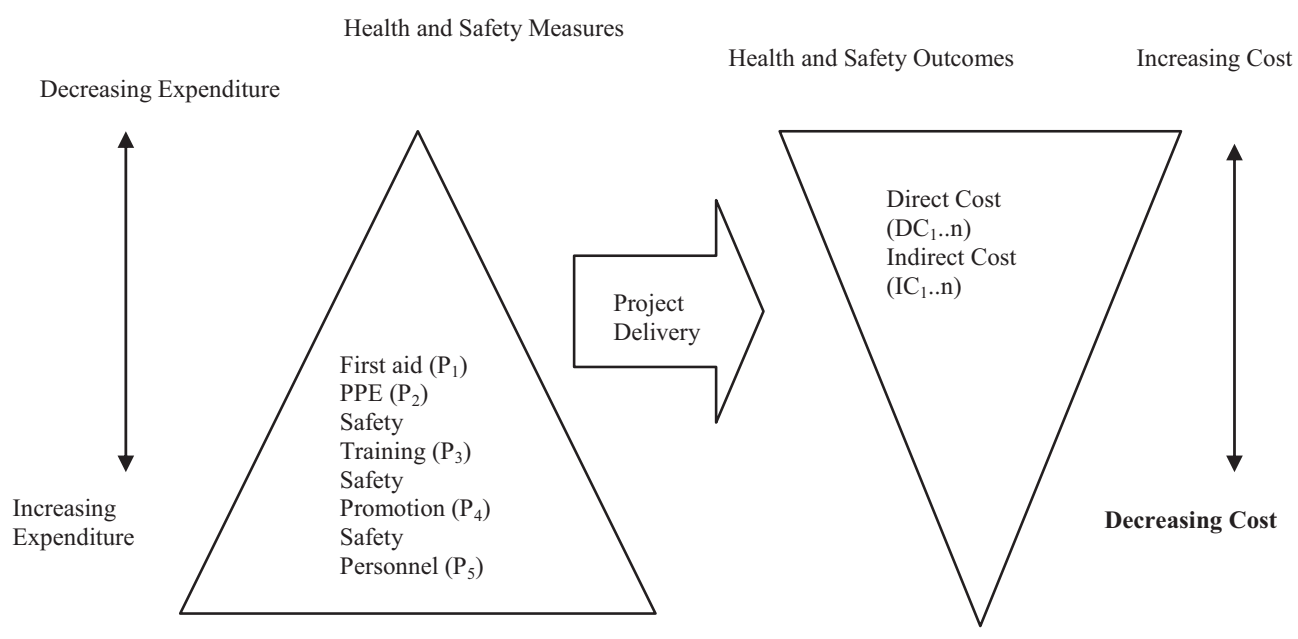

Figure 1: The relationship between cost of prevention and cost of accidents.

costs associated with accident occurrence. A logical progression of this argument is that the greater the investment in health and safety measures, the greater the reduction in accident costs. A simplified representation of this inverse relationship is shown in Fig. 1 which illustrates the argument that as less is expended on accident prevention and mitigation through first aid, PPE, safety training, safety promotion and safety personnel, during project delivery this translates into greater accident costs, both direct and indirect.

The proposition therefore, is that to secure greater reduction in the costs of accidents, there must be greater expenditure on health and safety measures. Table 3 lists the direct and indirect costs of accidents and the health and safety measures where costs must be expended to secure the reduction in costs. A significant challenge for contractors is to reduce accidents by taking effective action or measures to reduce the risks of accidents and ill health [15].

\section{BENEFITS OF ACCIDENT PREVENTION}

The benefits of accident prevention derive primarily from the savings that contractors make by not incurring the costs associated with accidents $[5,10,16]$. Consequently, it can be proposed that as costs associated with accidents decrease, contractors save more and therefore, there is a corresponding increase in the benefits derived by contractors. This inverse relationship is captured in Fig. 2, shows that similar to costs, benefits are direct and indirect as stated by Shearn [17], HSE [11], and Ferret and Hughes [4].

Whilst the quantum of costs and savings are not clear from Fig. 1, anecdotal evidence shows that investing in accident prevention can help reduce costs and consequently, provide benefits that are hard to ignore [6, 18]. In addition, HSE [16] demonstrated that reducing the costs of accident would avoid waste of both human and material resources. Moreover, the HSE [9] pointed out that human life, health and the well beings of future generations are priceless.

By extracting the relevant elements from the foregoing arguments and models, it is possible to evolve a conceptual framework that reflects the hypothesized relationship between expenditure on health and safety measures and benefits of accident prevention. In particular, the framework emphasizes the positive association between accident prevention expenditure and 
Table 3: Costs of accidents and their associated prevention costs.

\begin{tabular}{ll}
\hline Cost caused by accident & Prevention costs \\
\hline Worker illness & $\mathrm{P}_{1}, \mathrm{P}_{2}, \mathrm{P}_{3}, \mathrm{P}_{4}, \mathrm{P}_{5}$ \\
Cost related to damaged machinery/equipment & $\mathrm{P}_{3}, \mathrm{P}_{4}, \mathrm{P}_{5}$, \\
Accident insurance premium & $\mathrm{P}_{1}, \mathrm{P}_{2}, \mathrm{P}_{3}, \mathrm{P}_{4}, \mathrm{P}_{5}$ \\
Litigation cost & $\mathrm{P}_{1}, \mathrm{P}_{2}, \mathrm{P}_{3}, \mathrm{P}_{4}, \mathrm{P}_{5}$ \\
Loss due to damage or break of machinery & $\mathrm{P}_{3}, \mathrm{P}_{4}, \mathrm{P}_{5}$, \\
Losses related to working days & $\mathrm{P}_{1}, \mathrm{P}_{2}, \mathrm{P}_{3}, \mathrm{P}_{4}, \mathrm{P}_{5}$ \\
Losses incurred by contractors & $\mathrm{P}_{1}, \mathrm{P}_{2}, \mathrm{P}_{3}, \mathrm{P}_{4}, \mathrm{P}_{5}$ \\
Bad reputation & $\mathrm{P}_{1}, \mathrm{P}_{2}, \mathrm{P}_{3}, \mathrm{P}_{4}, \mathrm{P}_{5}$ \\
Waste disposal & $\mathrm{P}_{1}, \mathrm{P}_{2}, \mathrm{P}_{3}, \mathrm{P}_{4}, \mathrm{P}_{5}$ \\
Death & $\mathrm{P}_{1}, \mathrm{P}_{2}, \mathrm{P}_{3}, \mathrm{P}_{4}, \mathrm{P}_{5}$ \\
Permanent disability & $\mathrm{P}_{1}, \mathrm{P}_{2}, \mathrm{P}_{3}, \mathrm{P}_{4}, \mathrm{P}_{5}$ \\
Pains and discomfort & $\mathrm{P}_{1}, \mathrm{P}_{2}, \mathrm{P}_{3}, \mathrm{P}_{4}, \mathrm{P}_{5}$ \\
Increased absence & $\mathrm{P}_{1}, \mathrm{P}_{2}, \mathrm{P}_{3}, \mathrm{P}_{4}, \mathrm{P}_{5}$ \\
Damage to property/building & $\mathrm{P}_{3}, \mathrm{P}_{4}, \mathrm{P}_{5}$ \\
Fines and cost from prosecution & $\mathrm{P}_{1}, \mathrm{P}_{2}, \mathrm{P}_{3}, \mathrm{P}_{4}, \mathrm{P}_{5}$ \\
Cost of investigation & $\mathrm{P}_{1}, \mathrm{P}_{2}, \mathrm{P}_{3}, \mathrm{P}_{4}, \mathrm{P}_{5}$ \\
Cost of temporary labour & $\mathrm{P}_{1}, \mathrm{P}_{2}, \mathrm{P}_{3}, \mathrm{P}_{4}, \mathrm{P}_{5}$ \\
Cost related to recruitment and replacing competent worker & $\mathrm{P}_{1}, \mathrm{P}_{2}, \mathrm{P}_{3}, \mathrm{P}_{4}, \mathrm{P}_{5}$ \\
Cost of overtime payment & $\mathrm{P}_{1}, \mathrm{P}_{2}, \mathrm{P}_{3}, \mathrm{P}_{4}, \mathrm{P}_{5}$ \\
Cost of extra material & $\mathrm{P}_{3}, \mathrm{P}_{4}, \mathrm{P}_{5}$ \\
\hline
\end{tabular}

P1 = First aid, P2 = PPE, P3 = Safety training, P4 = Safety promotion, P5 = Safety personnel. Adapted from: Ref. [11].

Increasing Cost $\quad$ Cost of Accidents

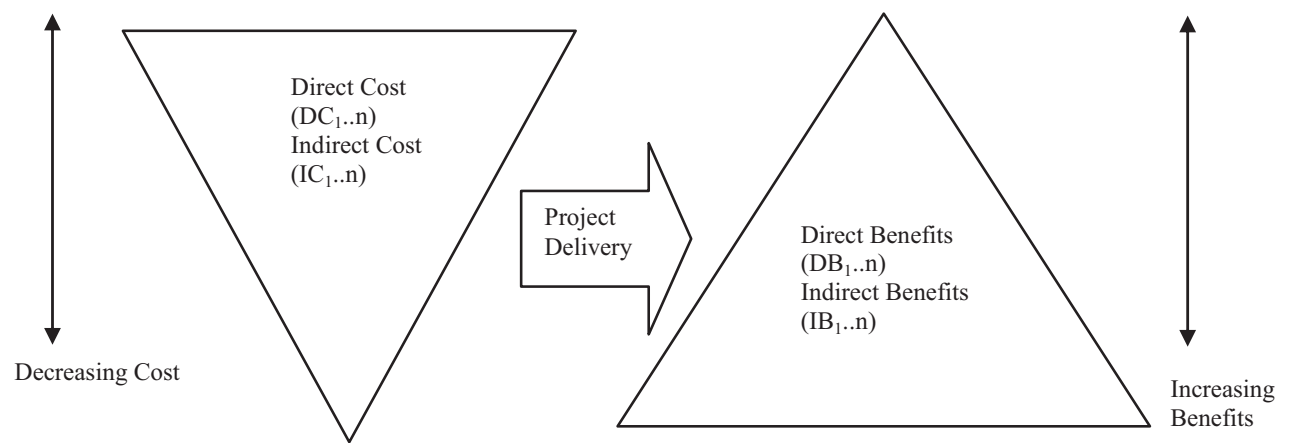

Figure 2: The relationship between cost of accidents and benefits of prevention.

the quantum of benefits. It also acknowledges that the benefits may be both direct and indirect, a fact which is crucial in ensuring that the process of quantifying the benefits captures all relevant benefits no matter how remote. This conceptual framework (Fig. 3) thus provides a robust platform for data collection for the purpose of CBA. 


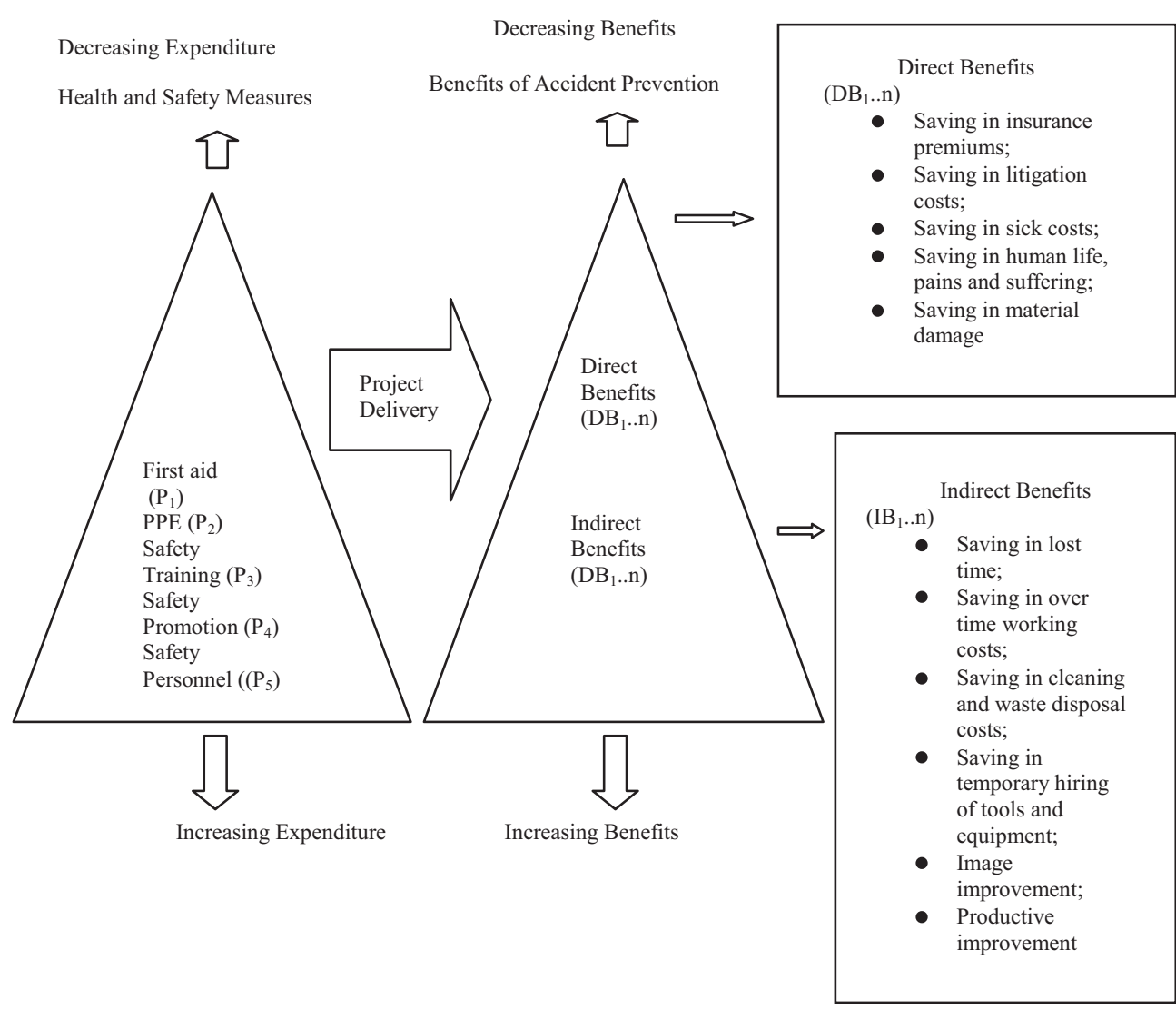

Figure 3: The components of accident prevention and associated benefits. Source: Refs. [4, 10], HSE (2005).

This key research question was addressed in the study:

- Will greater expenditure on accident prevention improve safety performance on construction sites, and yield greater benefits to contractors?

The research question was explored by application of a statistical technique: regression analysis, to the field data to develop the substantive model relating costs of accident prevention to the benefits accruing from such costs.

\section{RESEARCH METHODOLOGIES}

To address the key research question, quantitative methodological approach was adopted to investigate the costs and benefits of accident prevention. Naoum [19], Creswell [20], Anderson [21], Punch [22] described the quantitative research as an enquiry into social or human problem based on testing a theory composed of variables, measured with numbers and analysed using statistical procedures in order to determine whether the predictive generalisation of the theory hold true. Naoum [19] provided an example of quantitative methods as particularly important in businesses' where managers often talk about improving productivity, increasing return on investment, scheduling production, and forecasting demand, increasing customer 
service. Another major factor that influenced the choice of the quantitative survey strategy was the large and diverse nature of the research population (contractors) across the UK.

\subsection{Design of the survey questionnaire}

The questionnaire survey was designed primarily to elicit information from health and safety managers and similar personnel on costs and benefits of accident prevention so that the relationship between them could be explored using appropriate statistical techniques. These personnel were chosen because they are responsible for health and safety performance in the construction industry and are most knowledgeable on issues concerning health and safety performance. In the questionnaire, contractors were asked to estimate the total benefits accrued to their organizations as a result of action taken to prevent accidents such as cost savings on compensation claims, damaged materials/machineries, sick pay, lost time, litigation (fines and solicitors) and insurance premium in the last 12 months. On the costs of accident prevention, contractors were asked to estimate how much their organizations spent on health and safety measures (first aid facilities, PPE, safety promotion, training and personnel) in the last 12 months. These costs represented the independent variable of the model and some potential benefits of accident prevention were identified to represent the dependent variable.

\subsection{The variables in the study}

A variable is any characteristic that can vary across people or situations that can be of different levels or type [20, 23, 24]. There are two basic kinds of variables: dependent and independent [20]. These are independent and dependent variables.

The independent variable is that which the experiment manipulates or controls and as such is the variable in whose effect the researcher is interested while the dependent variable is the behavioural measure made by experimenter [20]. The independent variable in this study is the costs of accident prevention and the dependent variable is the benefit of accident prevention as outlined in Table 4. In the approach, the independent variable was compared to see its impact on the dependent variable. These variables were categorised into groups for comparison. The central goal was to obtain information on the dependent variable (benefits). Thus, by capturing data on these variables, data can be computed. Data on the variables are captured using purposively designed research instruments [20].

\subsection{Data collection}

The sample of respondents used in the survey was drawn from a database of contractors listed in the UK Kompass register [25]. A total of 500 (small 35\% $n=175$, medium 35\% $n=175$ and large $30 \% n=150$ ) were selected randomly across the UK to collect data on costs and benefits of accident prevention. With randomisation, a representative sample from a population provides the ability to generalise to a population [26]. In addition, the exact number of contractors (population size) in the research is large and unknown. The mathematics of probability proves that the size of the population is irrelevant and can be ignored when it is 'large' or unknown (cf. [27]). Population size is only likely to be a factor when working with a relatively small and known group. This means that a sample of 500 is equally useful in examining the opinions of a population of $15,000,000$ as it would a population of 100,000 (ibid) (cf. [27]). 
Table 4: Dependent and independent variables.

\begin{tabular}{ll}
\hline Dependent variables & \multicolumn{1}{c}{ Independent variables } \\
Total benefits of accident prevention & Costs of accident prevention \\
\hline Saving in insurance premiums & First aid facilities \\
Saving in litigation costs & PPE \\
Saving in sick costs & Safety training \\
Improving production and productivity rates and lowering & Safety promotion \\
accident rates & Safety personnel salary \\
Saving in sick pay cost & \\
Saving in lost time of other employees cost & \\
Saving in overtime working cost & \\
Saving in clean and waste disposal cost & \\
Saving in temporary hiring of tools and equipment & \\
Saving in working day lost cost & \\
Productivity improvement & \\
Image improvement &
\end{tabular}

Source: Refs. [4, 10, 11].

\subsection{Response rate}

A total of 79 questionnaires were received from the target sample representing $15.8 \%$ total response rate. It was reported in Takim et al. [28] that the response rate norm for postal questionnaire surveys is $20-30 \%$. Other sources that support this view include Black et al. [29] which reported a response rate of $26.7 \%$ for a questionnaire survey conducted stating that response rates in this region in construction surveys are not unusual at all. Although, the response rate obtained in this survey appears to be low compared with the standard response rate norm for postal questionnaire, indeed, lower response rates in the region of $14.7 \%$ [30] have been described as the 'norm' for comprehensive questionnaires. Sutrisna [31] even reported a response rate of $8.8 \%$ and [32] achieved a response rate of combined pilot and main survey of $15.42 \%$. Indeed, owing to the sensitive nature of the research, a response rate of $15.8 \%$ can be considered adequate.

\section{DEVELOPMENT OF A CBA MODEL}

A model is a mathematical abstraction that is an analogy of events in the real world [33]. It is written as an equation that defines a value that will predict $(\mathrm{Y})$ from one or more variables (X). Generally, regression analysis is a statistical technique that helps to determine the proportion of variance in preferably normally distributed dependent variable, accounted by one or more independent variables [20]. Simple linear regression was adopted to explore the relationship between costs and benefits of accident prevention. It was anticipated that the results of the linear regression model would reveal how well costs of accident prevention predict the benefits.

Regression analysis is usually concerned with the derivation of an equation which defines a best-fitting regression line [34]. The equation is in the form of:

$$
\mathrm{Y}_{\mathrm{i}}=\left(\beta_{0}+\beta_{1} \mathrm{X}_{\mathrm{i}}\right)+\varepsilon_{\mathrm{i}}
$$


where $Y_{i}=$ the outcome variable (dependent); $\beta_{0}=$ the value of the outcome when the predictor is zero; $\beta_{1}=$ the regression coefficient of the first predictor $\mathrm{X}_{\mathrm{i}} ; \varepsilon_{\mathrm{i}}=$ the difference between the predicted and observed value.

The coefficient $\left(\beta_{1}\right)$ provides the magnitude of the unique contribution that the independent variable makes to the dependent variable. This makes the simple linear regression particularly appropriate in this research which seeks to examine the influence of costs of accident prevention (independent variable) on benefits of accident prevention (dependent variable).

\subsection{Regression modelling}

Simple linear regression was applied to the data with the total costs of accident prevention to contractors included as the predictor variable and total benefits of accident prevention as the outcome variable. The results of the simple linear regression analysis shows that $47 \%\left(\mathrm{R}^{2}=0.47\right)$ of the proportion of variations in the benefits of accident prevention is explained by the variable costs of accident prevention. $\mathrm{R}^{2}$ is a measure of how good a prediction of the benefits of accident prevention can be made by knowing the predictor variable [35]. The $\mathrm{R}^{2}$ adjusted is 0.465 implying that the model explains $47 \%$ of the variations in the benefits of accident prevention within the population leaving 53\% unexplained.

The expenditure on accident prevention, thus, fails to explain all the possible variation in the benefits of accident prevention. Some plausible explanations for this result include the fact that there are also market forces at play, which directly and indirectly affect the magnitude of monetary benefits that organisations derive from accident prevention. For instance, savings in insurance premiums may, potentially, be due to the fact that organisations are free to switch insurance companies when they are more likely to obtain more competitive offers. Similarly, contractors can save on litigation costs just by changing solicitors. These factors are dictated by the market and because some of these market factors were not considered, it is not surprising that the linear model fails to explain all the variance in the outcome variable.

What is very clear from the statistics is that accident prevention measures, and the costs associated with implementing these measures, can be relied on as a basis for predicting the magnitude of financial benefits from accident prevention. The relationship between these two variables is captured in Table 5.

From Table 5, the model signifying the influence of costs of accident prevention on benefits of accident prevention to contractors could be expressed as:

\section{Total Benefits of Prevention $=10.142+2.001$ Total Costs of Prevention}

The above equation shows the unique monetary contribution that the costs of accident prevention make to the benefits of accident prevention. The unstandardized coefficient provides the relative measure of extra benefits from accident prevention. The results reveal that costs of accident prevention contribute extra benefits (unstandardized coefficient $=2.001, t=8.246$ and $p<0.005)$. In the model, the costs of accident prevention $(t=8.246, p<0.005)$ is a predictor of benefits of accident prevention and clearly makes a significant contribution to this model. That the $t$-statistic is $>2$ (rule of thumb) is a confirmation of the reliability of this estimate. A $t$-test is used to see whether each $\beta$ differs significantly. Each of these $\beta$ values has an associated standard error which is used to determine whether or not the $\beta$ value differs significantly from zero. The $t$-test associated with a $\beta$ value is significant (sig. $<0.005$ ), and the predictor 
Table 5: Coefficients.

\begin{tabular}{|c|c|c|c|c|c|c|c|c|}
\hline \multirow{2}{*}{\multicolumn{2}{|c|}{ Model $^{\mathrm{a}}$}} & \multicolumn{2}{|c|}{$\begin{array}{l}\text { Unstandardized } \\
\text { coefficients }\end{array}$} & \multirow{2}{*}{$\begin{array}{c}\begin{array}{c}\text { Standardized } \\
\text { coefficients }\end{array} \\
\text { Beta }\end{array}$} & \multirow[b]{2}{*}{$t$} & \multirow[b]{2}{*}{ Sig. } & \multicolumn{2}{|c|}{$\begin{array}{l}95 \% \text { Confidence } \\
\text { interval for B }\end{array}$} \\
\hline & & B & $\begin{array}{l}\text { Std. } \\
\text { Error }\end{array}$ & & & & $\begin{array}{l}\text { Lower } \\
\text { bound }\end{array}$ & $\begin{array}{l}\text { Upper } \\
\text { bound }\end{array}$ \\
\hline \multirow[t]{2}{*}{1} & Constant & 10.142 & 3.030 & & 3.347 & 0.001 & 4.107 & 16.178 \\
\hline & $\begin{array}{l}\text { Total preventive } \\
\text { cost }\end{array}$ & 2.001 & 0.243 & 0.687 & 8.246 & 0.000 & 1.518 & 2.484 \\
\hline
\end{tabular}

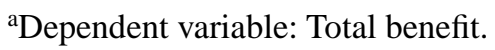

is making significant contribution to the model. The smaller the significance value the greater the contribution of the predictor [35].

From the magnitude of the $t$-statistics, the costs of accident prevention has a great economic impact on benefits of accident prevention. The model has a high statistical significance level indicated by a $p$-value of $<0.005$ for the F-statistics (Table 5). This indicates further that the independent variable accounts well for the variations in benefits of accident prevention. The positive coefficient $\left(\beta_{1}=2.001\right)$ confirms the positive relationship between costs of accident prevention and the benefits accruing thereof. This result implies that any expenditure on accident prevention will produce more benefits for contractors. It can, therefore, be inferred from this result that greater expenditure on accident prevention would improve health and safety performance on construction sites.

\section{DISCUSSIONS OF THE RESULTS AND THE IMPLICATION FOR HEALTH AND SAFETY MANAGEMENT}

The result of the regression shows that benefits of accident prevention are positively influenced by costs of accident prevention. This finding further reinforced the notion that costs of accident prevention are related to benefits of accident prevention as indicated above. The regression analysis shows that the more the contractors spend on accident prevention the greater the benefits they derived. These results imply that further expenditure on costs of accident prevention will produce greater benefits of accident prevention. They also imply that an additional cost of accident prevention is associated with extra benefits of accident prevention. The study also clarified the benefits of accident prevention. These results suggest that the benefits of accident prevention can contribute to a decline in accident occurrence in the construction industry. The study has several strengths. However, the study also has several limitations. Non-accidents costs such as death, pain and suffering of the affected worker and benefits such as savings in fatality, pain and suffering, job satisfaction, staff morale, stress were not considered in the study. There are many benefits of implementing health and safety management that cannot be easily evaluated in terms of money. These benefits are easy to overlook due to the difficulties of quantifying them in economic terms. The CBA model simply presents financial information that can be used to drive decision making. It demonstrates that there is a greater benefit arising from accident prevention and, by so doing, provides justification for a more proactive approach to accident prevention. Clearly on the basis of these results, there is strong business case for accident prevention. 


\section{CONCLUSIONS}

The CBA model was developed to explore the relationship between the preventative costs and benefits, with a view to drawing attention to the economic consequences of effective/ ineffective management of health and safety by contractors in the UK construction industry. Regression analysis was employed in the development of the model. The results of the regressions analysis indicate that any expenditure on costs of accident prevention will spring-up enormous benefits to contractors. The model should provide construction decision makers with valuable insight to compare costs and benefits of accident prevention to improve decision making in respect of health and safety issues/measures prior to commencement of site operations and during site operations.

The research offers a tool to contractors to capture cost outlays on accident prevention and use that as a basis for predicting the potential benefits of accident prevention. These findings will help contractors and indeed different stakeholders in the industry to make appropriate decisions, take suitable measures, and devote the necessary resources required for accident prevention on construction projects. In terms of 'costs of accident of prevention' the appropriate expenditure on these costs should provide a firm foundation towards improving their health and safety performance and, indeed, construction performance. This suggests that to help improve construction health and safety performance, contractors should spend more on costs of accident prevention.

In answering the research question, it was proved that greater expenditure on accident prevention improves safety performance on construction sites, and yield greater benefits to contractors. From the magnitude of the $t$-statistics and a high statistical significance level indicated by a $p$-value of $<0.005$ for the F-statistics, the results imply that any expenditure on costs of accident prevention will produce more benefits for contractors and improves safety performance on construction sites. It can be concluded that the cost of accident prevention significantly influences the overall benefits of construction industry.

Based on the findings of the research and the limitations that have been noted, a number of recommendations are put forward to provide some direction for future research endeavour in this domain. It is recommended that further research be undertaken to delve deeper into the costs of accident in undermining efforts to improve health and safety performance. Given that cost is an inevitable part of construction; such research will represent a significant contribution to knowledge. Within the scope of research, it was not possible to consider social costs such as death, pain and suffering of the affected worker and other costs or damage associated with human feelings. Future research could usefully be carried out in this important area. It is believed that these costs are significant losses to contractors, workers and society. The research can further be developed to explore social benefits of accident prevention such as savings in fatality, pain and suffering, job satisfaction, staff morale, stress so as to provide further evidence to guide contractors in their decision making on health and safety measures. Benefits from such a research could be wide ranging. However, this will require further data collection to test and improve the rigour of the model.

\section{REFERENCES}

[1] HSE, Occupational Health Statistic Bulletin 2005/06, Detailing Work-Related ill Health in Great Britain, http://www.industrialsafetytalk.com, 2007.

[2] Bomel Ltd, Improving health and safety in construction: data collection, review \& restructuring. HSE contract research report 387/2001. http://www.hse.gov.uk/research/ crr_pdf/2001/crr01387.pdf 
[3] Edwards, D.J. \& Nicholas, J., The state of health and safety in the UK construction industry with a focus on plant operator. Journal of Structural Survey, 20(2), pp. 78-87, 2001. doi:http://dx.doi.org/10.1108/02630800210433855

[4] Ferret, E.D. \& Hughes, P., Introduction to Health and Safety in Construction, 2nd edn, Elsevier Ltd.: UK, 2007.

[5] Boot, T., Georgios, D. \& Panopoulos, D.G., Economic aspects of safety in construction industry. 3rd International Conference on Construction in the 21st Century (CITC-III) Advanced Engineering, Management and Technology, 15-17, September 2005, Athens, 2005.

[6] Lancaster, R., Ward, R., Talbot, P. \& Brazier, A., Costs of compliance with health and safety regulations in small and medium enterprises (SME) HSE. Research Report, 174, 2003.

[7] Oxenburgh, M. \& Marlow, P., The productivity assessment tool: computer based cost benefit analysis model for the economic assessment of occupational health and safety interventions in the workplace. Journal of Research-ECON Proceeding, 36, pp. 209-214, 1996.

[8] Fellows, R., Langford, D., Newcombe, R. \& Urry, S., Construction Management in Practice, 2nd edn, Blackwell Science Ltd: Oxford, 2002.

[9] HSE, Occupational Health Statistic Bulletin 2003/04, Detailing Work-Related ill Health in Great Britain, http://www.industrialsafetytalk.com/news/hea/hea138.html, 2004.

[10] Tang. S.L., Ying, K.C., Chan, W.Y. \& Chan, Y.L., Impact of social safety investments social costs of construction accidents. Journal of Construction Management and Economics, 22, pp. 937-946, 2004.

[11] HSE, Health and Safety in Construction Industry, http:// www.hse.gov.uk/index.htm, 2006.

[12] Everret, J.G. \& Frank, B.P., Costs of accidents and injuries to the construction Industry, Journal of Construction Engineering and Management, pp. 158-164, 1996.

[13] Lindqist, K. \& Lindholm, L.A., Cost-Benefit Analysis of the Community Based Injury Prevention Programme in Motala, Sweden-a WHO. Safe Community, 2001.

[14] Sutrisna, M., Developing a Knowledge Based System for the Valuation of Variations in Civil Engineering Works, Unpublished PhD Thesis, University of Wolverhampton, Wolverhampton, 2004.

[15] Lanoie, P. \& Tavenas, S., Costs and benefits of preventing workplace accidents: the case of participatory ergonomics. Journal of Safety Science, 24(3), pp. 181-196, 1996.

[16] HSE, Comprehensive Statistics in Support of the Revitaliz Health \& SafetyProgramme, gov.uk/statistics/books.htm\#fnf, 2005.

[17] Shearn, R.C., Case Example: Business Benefits Arising From Health And Safety, Health \& Safety Laboratory, 2003.

[18] Holt, A.S.J., Principles of Construction Safety. Blackwell Science Ltd Health in Great Britain: London, 2001.

[19] Naoum, S.G., Dissertation Research and Writing for Construction Students. Elsevier Butterworth-Heinemann Ltd: UK, 1998.

[20] Creswell, J.W., Research Design: Qualitative, Quantitative, and Mixed Method Approaches, Thousand Oaks. Sage Publication: California, 2003.

[21] Anderson, V., Research Method in Human Resource Management. Charter Institute of Personnel \& Development Publication, 2004. 
[22] Babbie, E.R., Survey Research Methods. Wadsworth Publication Company: Belmont, CA, USA, 1990.

[23] Hammond, S. Breakwell, M.G. \& Fife-Schaw, C., Research Methods in Psychology. 2nd edition, Sage Publication Ltd: London, 2000.

[24] Burns, B.R., Introduction to Research Methods, 4th edition. Sage Publication Ltd.: London, 2000.

[25] Kompass, The authority of British Industry Vol. 1. Products and Services. Reed Information Services: East Grinstead, 2006.

[26] Cheng, J., The Impact of Strategic Discussion on Construction Client Satisfaction: An Assessment Framework. Unpublished PhD Thesis, University of Wolverhampton, 2008.

[27] Punch, K.P., Developing Effective Research Proposals, 3rd edn, Sage Publication Ltd: $\mathrm{UK}, 2005$.

[28] Takim, R., Akintoye, A. \& Kelly, J. Analysis of performance measurement in the Malaysian construction industry. Globalization and Construction, eds S.O. Ogulana, C. Chareonngam, P. Herabet \& B.H.W. Hadikusumo, AIT Conference Centre: Bangkok, Thailand, pp. 533-546, 2004.

[29] Black, C., Akintoye, A. \& Fitzgerald, E., An analysis of success factors and benefits of partnering in construction. International Journal of Project Management, 18, pp. 423-434, 2000.

[30] Soetanto, R., Proverbs, D.G. \& Holt, G.D., Achieving quality construction projects based on harmonious working relationships: clients' and architects' perceptions of contractor performance. International Journal of Quality and Reliability Management, 18(4), pp. 528-548, 2001.

[31] Sutrisna, M., Developing a Knowledge Based System for the Valuation of Variations in Civil Engineering Works, Unpublished PhD Thesis, University of Wolverhampton, Wolverhampton, 2004.

[32] Ankrah, N.A., An Investigation into the Impact of Culture on Construction Project Performance. Unpublished PhD Thesis, University of Wolverhampton, 2007.

[33] Motulsky, H.M.D, Intuitive Biostatistics. Oxford University Press Ltd.: New York, USA, 1995.

[34] Fleming C.M. \& Nellis G.J., Principles of Applied Statistics. Routledge Publication Ltd.: London, 1994.

[35] Field, A., Discovering Statistics, Using SPSS for Windows, 2nd edn. Sage Publications Ltd.: London, 2005.

[36] HSE, Occupational Health Statistic Bulletin 2007/08, Detailing Work-Related ill Health in Great Britain, http://www.industrialsafetytalk.com, 2009. 